Kari Kallioniemi

FT, kulttuurihistoria, Turun yliopisto

Kimi Kärki

FT, kulttuurihistoria, Turun yliopisto

\title{
POPULAARIKULTTUURIN ESTETISOIMA JA NORMALISOIMA NATSISMI
}

Natseja käsittelevää populaarikulttuuria on tutkittu vaihtelevasti, lähinnä eksploitaation ja internetin komediallisen meemikulttuurin näkökulmasta. Parhaan mediatutkimuksellisen esityksen on laatinut väitöskirjassaan Nazityskland i populärkulturen Eva Kingsepp Tukholman yliopistosta (2008), mutta kulttuurihistoriallinen kokonaistulkinta aiheesta puuttuu. Sellainen tarvittaisiin erityisesti siksi, että populaarikulttuurin tuotteet alkavat korvata tutkimuksen tuottaman historiakuvan.

Graalin malja tuottamassa energiaa Hitlerin hallitsemalle kaupungille onton maapallon sisällä? Hitler ratsastamassa Blondi-nimisellä dinosauruksella Kuun pimeällä puolella? Vuoden alussa teattereissa ensi-iltansa saanut Iron Sky: The Coming Race (Timo Vuorensola, 2019) pitää sisällään nämä kohtaukset ja on kuvaava esimerkki natsien ja heidän perintönsä vallattomasta hyödyntämisestä tämän päivän populaarikulttuurissa. Elokuva on noin 20 miljoonaa euroa maksanut jatko-osa Iron Skylle (Vuorensola, 2012), jossa sodan hävinneet natsit pakenivat kuun pimeälle puolelle ja rakensivat sinne hakaristin muotoisen tukikohdan. Parodista inspiraatiota on haettu niin Edward Bulwer-Lyttonin romaanista Vril: tuleva rotu (The Coming Race, 1871), Jules Vernen klassisesta poikakirjasta Matka maan keskipisteeseen (Voyage au centre de la Terre, 1864) kuin internetin liskoihmis-salaliittoteorioista.

Elokuvasarjalle on tekeillä myös kolmas osa, The Ark - An Iron Sky Story, joka osin Kiinassa tehtynä on varmasti tarkoitettu myös sikäläisille markkinoille. Elokuvassa kaksi kiinalaista yliopistosta pois potkittua opiskelijaa kiinnostuu kuusta vastaanottamastaan mystisestä viestistä, joka vie heidät taistelemaan kaikkien salaliittoteorioiden äitiä, Illuminati-järjestöä vastaan. Mielenkiinnolla voi odottaa, miten kiinalainen yleisö, ja varsinkin viranomaiset, suhtautuvat "syrjäytyneisiin" opiskelijoihin elokuvan päähenkilöinä ja sen joukkorahoituksella tuotettuun nörttimäiseen ja groteskiin camp-huumoriin. Iron Skyn maailma pohjaa länsimaisessa populaarikulttuurissa viimeisen 40 vuoden aikana kehittyneeseen parodiseen tyylilajiin, jolle esimerkiksi juuri natsit ja heidän edustamansa perintö ovat jatkuvan fasinaation ja attraktioiden kohde.

Ainakin Iron Sky: The Coming Race on selkeästi kommentti nykyisen mediatodellisuuden epäluotettavuuteen, somekupliin ja salaliittoparanoiaan. Elokuvan kantava slogan on tutulta kuulostava "Let's make Earth great again". Trumpin sijasta Yhdysvaltain presidentti on kuitenkin edelleen Sarah Palinia muistuttava nainen, joka edustaa onton maapallon sisällä asustavia ja ihmiskunnan johtajiksi soluttautuneita 


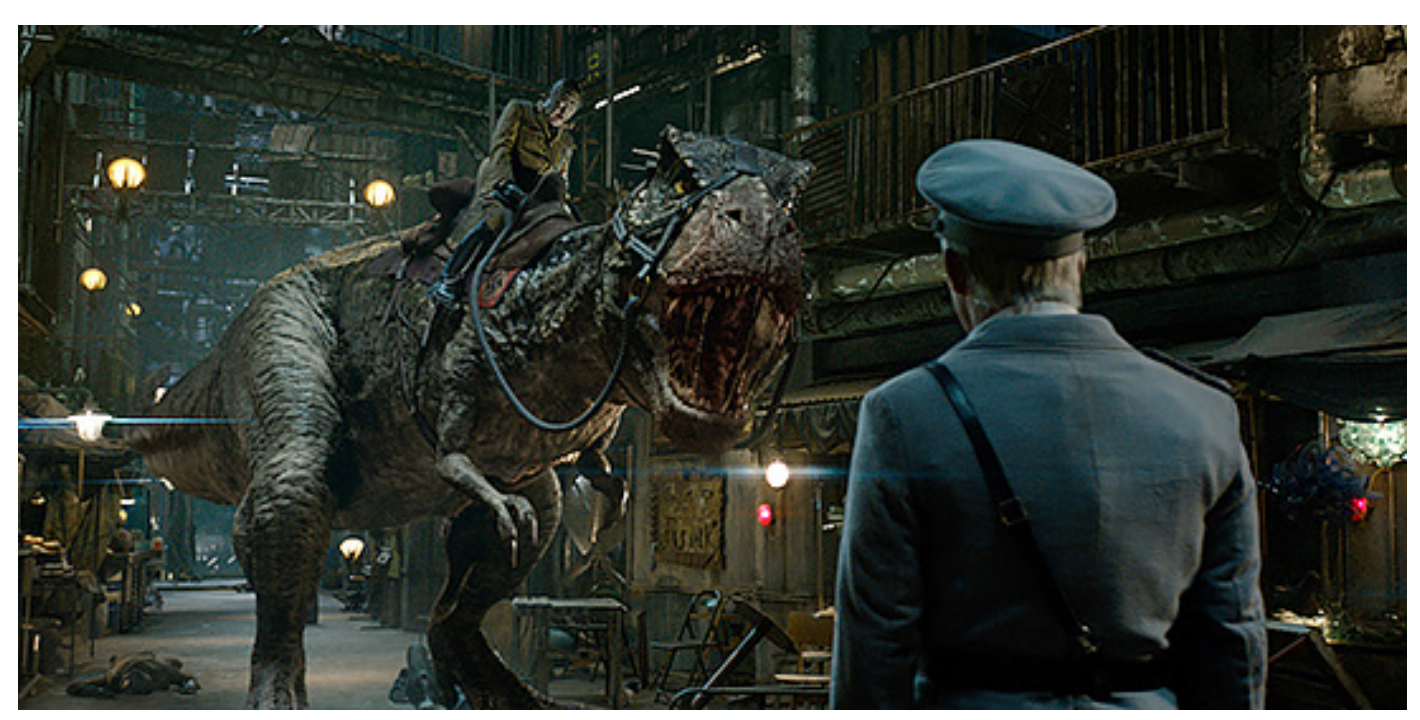

Dinosauruksella ratsastava Hitler Iron Sky: Coming Race -elokuvassa. Kuva: Iron Sky Universe.

Vril-liskoja. Maapallon pinta on tuhoutunut ydinsodassa ja ihmiskunnan rippeet asuvat kuun pimeällä puolella sijaitsevassa natsitukikohdassa, joka tuli tutuksi jo ensimmäisestä Iron Sky -elokuvasta.

Tämä kaikki on vain tuore jäävuoren huippu siitä valtavasta määrästä natseihin ja natsismiin liittyvää populaarikulttuuria, jota läntisessä maailmassa on tuotettu toisen maailmansodan jälkeen. Suomalaisessa yhteiskunnassa kiistellään siitä, voivatko mielenosoittajat esiintyä kadulla hakaristilippujen kanssa, ja Saksassa siitä, voiko Adolf Hitlerin esittää Wolfenstein II: The New Colossus -videopelin (2017) saksankielisessä versiossa viiksien kanssa (Similä 2018, B1-B3). Helsingin kaupunginteatterin esityksessä suositusta sanomalehtisarjakuvasta Hitler saa kuitenkin rauhassa kalastella Fingerporinlahdella. Musiikkivideot taas hyödyntävät siekailematta Hitlerin propagandaelokuvaohjaaja Leni Riefenstahlin elokuvien estetiikkaa ja suoria kohtauksia (esim. Rammstein: Stripped, 1999). Populaarimusiikki, Hitler-meemit, videopelit ja erilaiset natsismia käsittelevät taide- ja eksploitaatioelokuvat saivat äskettäin myös rinnalleen prestiisitelevisiosarjat, Man in the High Castle (2015-) ja SS-GB (2017), jotka perustuvat Philip K. Dickin (1962) ja Len Deightonin (1978) samannimisiin romaaneihin. Niistä ensin mainitussa natsit ovat jakaneet japanilaisten kanssa Yhdysvaltain herruuden sodan jälkeen ja jälkimmäisessä Hitler on voittanut itselleen vielä Britannian. Myös nämä tv-sarjat käyttävät siekailematta hyväkseen äärioikeiston ja alt-rightin nousun aikaansaamaa levottomuutta ja synnyttävät katsojassa epämiellyttävän ja kutkuttavan tunteen maailmasta, joka on peruuttamattomasti muuttunut fasistiseksi. Samanaikaisesti tällaiset vaihtoehtohistoriat tai jopa vaihtoehtotodellisuudet - tieteiskirjallisuudesta tutut rinnakkaiset ulottuvuudet - ovat kriittisiä kommentteja nykyiseen yhteiskunnalliseen todellisuuteen. Niiden ideat leviävät poliittiseen retoriikkaan, kaduille ja nettiin, sekä fasistisissa että antifasistisissa meemeissä ja mielenilmauksissa.

\section{Natsiviihteen historiaa}

Onko populaarikulttuuri ja audiovisuaalinen media jollain tavalla normalisoinut natsit ja heihin liitetyn synkän eurooppalaisen perinnön tekemällä heistä merkittävän 
osan viihdekulttuurin kuvastoa? Vai onko kyseessä eräänlainen nykypäivään sovellettu antifasistinen projekti, jonka avulla erilaisia yleisöjä varoitetaan niistä vaaroista, jotka uhkaavat yhteiskuntaa, jos demokraattisia instituutioita kyseenalaistetaan tai vähätellään liiaksi? Kaiken kaikkiaan on kyse kulttuurin, taiteen, politiikan ja ideologioiden välisistä kytköksistä, jotka fasismin ja natsismin kohdalla ovat muuttuneet viime aikoina entistä monimutkaisemmiksi. Natseja ja fasisteja käsittelevien elokuvien lähes yksiselitteinen tehtävä 1960-luvun lopulle asti oli antifasistinen. Tavoite oli varoittaa kansalaisia äärioikeistolaisen ideologian vaaroista ja juhlia liittoutuneiden voittoa Natsi-Saksasta, esimerkiksi Korkeajännitys-sarjakuvan (Commando, 1961-) hurtissa lad-hengessä. Hollywoodin elokuvaviihde ja BBC:n laatusarjat pyrkivät hienovaraisemmin myös natsien inhimillistämiseen. Inhimillisiä natseja olivat esimerkiksi tunnontuskia kärsivä Marlon Brandon näyttelemä natsiupseeri elokuvassa Nuoret leijonat (Young Lions, Edward Dmytryk, 1958) tai Bernard Heptonin ajoittain lähes englantilaista herrasmiestä muistuttava vankilinnan komentaja tv-sarjassa Vankileiri Colditz (Colditz, 1972-1974). Vuonna 1967 Yhdysvalloissa ilmestyi kaksi valtavirran tuotantoa, jotka kyseenalaistivat perinteisen kaavan esittää natsit: Kenraalien yö (Night of the Generals, Anatole Litvak) ja Kevät koittaa Hitlerille (The Producers, Mel Brooks). Ensin mainitussa Peter O'Toole esittää natsiupseeria, joka on Jack the Ripper -henkinen sarjamurhaaja. Hänen murhanhimonsa saa kimmokkeen Louvren taidemuseossa koetuista hetkistä kielletyn "rappiotaiteen" parissa. Jälkimmäisessä Hitlerin rooli musikaaliesityksessä annetaan beatnik-hahmon kaltaiselle hipille. Uudempi esimerkki eksentrisestä "natsinerosta" on Inglorious Basterds -elokuvan (Quentin Tarantino, 2009) SS-Standartenführer Hans Landa, jota esitti sivuosaOscarin arvoisesti Christoph Waltz.

Natsiestetiikkaa on hyödynnetty antifasistisesti myös populaarimusiikin piirissä ja mahtipontisissa musiikkielokuvissa. Pioneereja tässä suhteessa olivat esimerkiksi Peter Watkinsin Privilege (1967), Ken Russellin Lisztomania (1975) ja Alan Parkerin The Wall (1982), jotka kommentoivat totalitaristista spektaakkelien tuotantoa. Kaikissa hyödynnetään natsistista estetiikkaa, mutta rajanvetoa antifasismin ja fasismiin kohdistuvan fasinaation välille on vaikea vetää. Näiden elokuvien perusajatus on kuitenkin musiikin suggeroivasta voimasta varoittaminen ja konserttikokemuksen hurmoksen vertaaminen kansallissosialistiseen joukkokokoukseen.

Nyt Pandoran lipas oli avattu. Esimerkiksi Luchino Viscontin wagneriaaninen taide-elokuva natsien kanssa veljeilevän teollisuussuvun traagisesta kohtalosta Kirotut (Götterdammerung, 1969) ja Liliana Cavanin natsiupseerin ja hänen keskitysleirivankinsa sadomasokistisesta suhteesta kertova taidedraama Yöportieri (The Night Porter, 1974) pyrkivät laajentamaan antifasistista sanomaa. Gavriel D. Rosenfeldin (2015) mukaan tämä eksploitaatioprosessi on johtanut tähän päivään tultaessa natsismin normalisointiin. Tästä on seurannut natsismin ja holokaustin rikosten suhteellistaminen ja vähättely - esimerkiksi suhteessa Stalinin tekemiin puhdistuksiin - ja natsismin perinnön universalisoituminen. Japanissa SS-uniformuun pukeutuva roolipelaaja ei välttämättä tiedosta asunsa alkuperää, eikä itsestään ja kavereistaan Auschwitzissa selfieitä ottava nuori ymmärrä kunnioittaa holokaustin uhreja ja sen mittakaavaa ja käyttäytyy siksi kuin millä tahansa turistikohteella.

\section{Estetiikka on korvannut historiatajun?}

Kaiken kaikkiaan Rosenfeld puhuu kriittiseen sävyyn "yhteisen historiatajun katoamisesta" (2015, 7-14) ja siitä, kuinka populaarikulttuurin ja viihdeteollisuuden luomat visiot ja mallit ovat alkaneet korvata opettajien ja ammattihistorioitsijoiden esittämää kuvaa menneisyydestä. Tässä yhteydessä hänen esittämänsä kolmas nä- 
kökulma, natsismin estetisoituminen, on populaari- ja mediakulttuurin tutkimuksen kannalta mielenkiintoisin. Jo 1970-luvun puolivälissä yhdysvaltalainen kriitikko ja esseisti Susan Sontag kiinnitti esseessään Leni Riefenstahlista huomion siihen, kuinka tämän luoma estetiikka natsien propagandaelokuvissa oli alkanut saada yhä enemmän hyväksyntää. Hyväksyvä kiinnostus natseja ja erityisesti natsiestetiikkaa kohtaan oli alkanut Sontagin (1975) mielestä johtaa suoranaiseen fasinaatioon natsismia kohtaan. Tämä ilmeni niin sen parodisena kuin eksploitatiivisena käyttönä populaarikulttuurissa: fasismin utooppisen kuvaston vetovoima, fasististen johtajien eroottinen vetovoima ja seksuaalisen vapautumisen ajanhenkeen sopiva seksuaalinen seikkailullisuus tekivät SS-uniformusta ikonisen elementin osaksi "kinkyä" erotiikkaa. Natsit asettuivat kiehtovuudessaan muun kauhuromantiikan mielikuvituksellisen hirviögallerian - okkultistien, vampyyrien ja fantasiaolentojen - rinnalle.

Tietenkin myös aivan suoraa natsismia on todistettu populaarimusiikin piirissä. Tästä esimerkkejä ovat natsipunkkareiden ja NSBM-skenen (National Socialist Black Metal) eri tavoin valkoista ylivaltaa kaihoavat yhtyeet, kuten Screwdriver, Brutal Attack, Absurd ja Goatmoon. Niidenkin tapauksessa ollaan siinä mielessä ajan hengen ytimessä, että ympäri Eurooppaa nousevat populistiset liikkeet sisältävät myös transgressiivisten nuorisoalakulttuurien jäseniä, jotka vastustavat niin juutalaisia kuin muslimeja ja ihannoivat pohjoisten mytologioiden sinisilmäisiä sankareita.

Populaarikulttuuri ei tietenkään voi olla ensisijainen historiatietoisuuden synnyttäjä, mutta sillä voi olla suuri vaikutus tämän tietoisuuden muotoutumiseen ja esimerkiksi natseja koskeviin mielikuviin. Populaarikulttuuriset kierrätykset natsistisesta kuvastosta ovatkin olleet ongelmallisia juuri siksi, että sama estetiikka palvelee sujuvasti hyvinkin vastakkaisia tarkoitusperiä. Voidaankin ajatella, että natsistisen kuvaston kulttuurihistoria ja populaarikulttuuri tuottavat uudenlaisen luokittelujärjestelmän tarpeen. Rosenfeldin yritys tehdä tällainen analyysi jättää kuitenkin huomiotta populaarikulttuurisen fasinaation aiheeseen. Hän ei siis juuri pohdi aiheen affektiivisuutta ja mielihyvän kytkentöjä. Artikkelikokoelma $\mathrm{Na}$ zisploitation! (2012) taas keskittyy pääasiassa vain taide- ja eksploitaatioelokuviin ja supersankarikuvastoon. Tarvitaan tutkimusta, joka huomioi koko audiovisuaalisen kulttuurin kentän suhteessa natsistisen kuvaston hyödyntämiseen. Tätä kautta voitaisiin saavuttaa kulttuurihistoriallinen kokonaistulkinta, joka auttaisi ymmär-

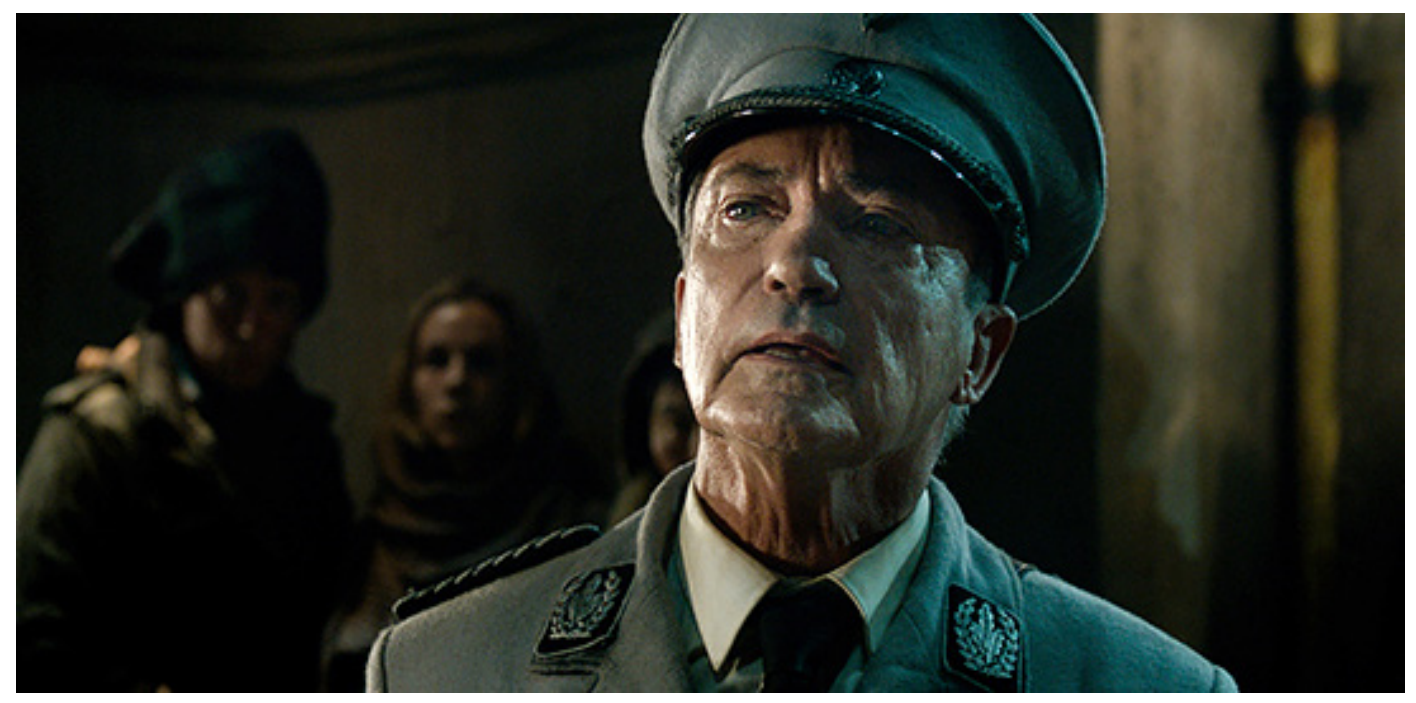

Udo Kier kuunatsien johtajana elokuvassa Iron Sky: Coming Race. Kuva: Iron Sky Universe. 
tämään myös nykyistä poliittista myllerrystä suhteessa fasismin fasinaatioon. Edes Eva Kingseppin laaja-alainen väitöskirja natsipopulaarikulttuurista ei käsittele tätä. Vaaditaankin hyvää medialukutaitoa ja historiatajua, jotta kulloinenkin konteksti ja esittäjien tarkoitusperät avautuvat kunnolla. Esimerkiksi Iron Sky: The Coming Race -elokuvan sound trackista vastasi 1980-luvulla perustettu slovenialainen kontroversiaali yhtye Laibach. Se on leikitellyt totalitaristisella estetiikalla, univormuilla, marssirummuilla ja militarismilla, irvaillen niin natsismille, kommunismille kuin kapitalismille. Iso mediatapaus yhtyeen uralla oli heidän keikkansa Pohjois-Koreassa, josta tehtiin myös dokumenttielokuva The Liberation Day (Morten Traavik, 2016). Yhtye sopiikin imagonsa ja taustansa vuoksi hyvin elokuvan soundtrackille. Iron Sky: The Coming Race ei vaikuttanut saavan kovin hurmioitunutta vastaanottoa (Typpö 2019, B4), mutta elokuva kommentoi tyylilajissaan kiinnostavasti koko fasistisen fasinaation kuvaston problematiikkaa ja sen poliittisia ulottuvuuksia. Laibachin käyttö elokuvassa kertoo tekijöiden ymmärryksestä fasinaation kerroksellisuutta kohtaan. Kun yhtyeen laulaja Milan Fras toteaa elokuvan alkupuolella "Let's Make Earth great again", kyseessä on kuin totalitaristinen käsky parantaa maailma - itsessään suuri paradoksi.

\section{Lähteet}

Kingsepp, Eva (2008) Nazityskland i populärkulturen. Minne, myt, medier. Doktorsavhandling i medie- och kommunikationsvetenskap vid Stockholms universitetet. Stockholm: Stockholms universitet.

Magilov, D. H., Vander Lugt K. T. \& Bridges, E. (2012) Nazisploitation! The Nazi Image in Low-Brow Cinema and Culture. London: Continuum.

Rosenfeld, Gavriel (2015) Hi Hitler! How the Nazi Past is Being Normalized in Contemporary Culture. Cambridge: Cambridge University Press.

Similä, Ville (2018) "Äärimmäisen ankaraa natsisymbolien kieltoa lievennettiin hieman Saksassa: Hitler sai viiksensä takaisin". Helsingin Sanomat 15.12.2018, B1-B3.

Sontag, Susan (1975) "Fascinating Fascism". The New York Review of Books, 305-325.

Typpö, Juho (2019) "Uusi Iron Sky on valtava pettymys". Helsingin Sanomat 18.1.2019, B4-B5. 